\title{
The strategy of digital scenic area planning from the perspective of intangible cultural heritage protection
}

\author{
Yue Zhang ${ }^{1}$, Mingqing $\operatorname{Han}^{1 *}$ and Weiwei Chen ${ }^{2}$
}

\begin{abstract}
Intangible cultural heritage has the characteristics of regionality, uniqueness, and liveness. Its protection and inheritance are faced with many challenges, and can be resolved by integrating with the scenic areas. The construction of digital scenic areas is an effective way to achieve a win-win situation. Based on resource characteristics and market positioning analysis of the Celadon Cultural Industrial Park, the construction objectives and coping strategies of the scenic area are proposed by systematically introducing the digital technology in the scenic area planning, project initiation, tourism management model, and other aspects to create a culture-first, three-dimensional virtual reality scenic area.
\end{abstract}

Keywords: Intangible cultural heritage (ICH), Digital tourist attraction, Longquan celadon, Spatial information technology

\section{Introduction}

United Nations Educational, Scientific, and Cultural Organization (UNESCO) passed the "Convention for the Safeguarding of the Intangible Cultural Heritage" on October 17, 2003, and in 2004 China officially acceded to this convention. In March 2005, the General Office of the State Council of China issued "the Opinions on Strengthening the Safeguarding of Intangible Cultural Heritage (ICH) in China," which put forward the objectives, guidelines, principles, and protective measures for safeguarding intangible cultural heritages in China, and set up an intangible cultural heritage masterpiece listing system. In 2011, the government promulgated the "Law of the People's Republic of China on the Intangible Cultural Heritage," which legally emphasized on and strengthened the protection and inheritance of $\mathrm{ICH}$, and officially defined the $\mathrm{ICH}$ as follows: various traditional cultural expressions that people of all the ethnic groups passed down from generation to generation and regarded as part of their cultural heritage, and substance and locations related to the traditional cultural expressions. Specifically, it includes oral literature and carrier language, traditional arts, traditional skills, medicine and calendar, folk customs and festivals, traditional sports and entertainment, and others in six

\footnotetext{
* Correspondence: hmq@zucc.edu.cn

'Zhejiang University City College, Hangzhou, Zhejiang, China

Full list of author information is available at the end of the article
}

categories [1]. As early as the 1970s, researchers and scholars have used technologies such as photography and sound recording technology to record and preserve various ICH (such as cultural relics and archeological discoveries) [2]. In 1990, the Digital Michelangelo project initiated in Standard University in the United States set the precedence for digital protection of cultural heritage. With rapid development of information technology in the world, many countries and UNESCO vigorously promoted the digital protection of $\mathrm{ICH}$ [2-5]. At present, the digital protection of $\mathrm{ICH}$ in our country has gradually become an important means of protecting ICH resources.

ICH represents the spiritual height of human cultural heritage, and has gradually become an important part of tourism resources. In the process of promoting the $\mathrm{ICH}$ protection, local governments have realized that the combination of ICH and tourism development is a harmonious way for both protection and utilization, which not only creates a good ICH environment but also promotes the exploitation and inheritance of the value of ICH through tourism development [4]. But how can the combination of tourism development and heritage protection be optimized?

The existing literature on the protection of $\mathrm{ICH}$ can be mainly divided into theoretical research or empirical research. There are literatures that tried to interpret the role and significance of $\mathrm{ICH}$ in tourism development 
from the tourism perspective. There is only a few interdisciplinary research on the interaction of the $\mathrm{ICH}$ protection and tourism development. It is even rarer to find researches that explore the interaction between the $\mathrm{ICH}$ protection and tourism development from the perspective of scenic planning using geographic information system (GIS) 3D space technology, since it is a challenging multidisciplinary topic that involves $\mathrm{ICH}$, tourism, planning, and geography.

The ICH has the characteristics of regionalism, uniqueness, activeness, inheritance, mobility, comprehensiveness, nationality, and so on. It is an important direction of development to establish a digital scenic area different from traditional tourism services and contents, through collection, processing, integration, storage, transmission, and application of a variety of $\mathrm{ICH}$ information, in combination with various resource elements, like geo-spatial environment of tourist attractions [2-8]. ICH is always dynamically changing in time and space. Therefore, it is imperative to make comprehensive, real, and systematic records of ICH that is precious, endangered, and has historical value. The digitization of tourist attractions not only satisfies the protection needs of inheritance and evolution of ICH but also boost the competitiveness and service capability of tourist attractions by recreating in the virtual space the true historical and geographical information of the ICHs through the temporal-spatial information technology. The digitalized information could then be present to the general public in an intuitive way to greatly increase tourists' experience and realism $[5,6]$.

Porcelain is a witness of human civilization. The world got to know China through porcelain. The ancient Chinese porcelain firing techniques are an outstanding contribution to human civilization, and had been continuously advancing along with the development of society, with countless peerless boutiques being created. Celadon is deemed as the mother of porcelain, and has a history of nearly two thousand years from the original celadon in the Shang and Zhou Dynasties to the more mature celadons since the Eastern Han Dynasty, from the "Enamel" of the Jin Dynasty, the "Secret Color Porcelain" of the Yue Kiln in the Tang Dynasty to the Longquan celadon. From the bluish yellow and light yellow color of the early stage celadons to the later blue-green celadons, many different color celadons have been made, but the blue-green color has always been the fashion. Longquan Kiln Celadon is the most brilliant pearl among all the celadons. The firing of Longquan celadon began more than 1700 years ago, and reached its peak in the Song Dynasty. It is a celadon kiln system with the longest firing period, the widest kiln site distribution, the highest product quality requirements, the largest production scale, and impacting area of export in China or even in the world. On September 30, 2009, at the fourth meeting of the UNESCO Intergovernmental Committee for intangible cultural heritage protection, Zhejiang Longquan Celadon traditional firing techniques were officially listed in the List of Human ICH masterpieces, making it the first and only one selected $\mathrm{ICH}$ porcelain item in the world.

Longquan celadon is a common wealth of the whole world, and moreover it is a special tourism resource. However, due to its age, most of the kiln sites have been broken, deeply buried, and scattered. Currently, 395 kiln sites in Longquan are found. To present this precious heritage in a complete and genuine way, and preserve the regional imprint of the $\mathrm{ICH}$, it is necessary to use the GIS method to gather Longquan celadon ICH data including text, image, audio, video and other data formats, as well as the actual scenes and data of multiple kiln sites on the terminal display platform to realize digital protection of the $\mathrm{ICH}$, and at the same time, integrate the $\mathrm{ICH}$ with the tourism environment to promote synchronized protection and development, and use virtual reality technology to give tourists a real space perception. Longquan Celadon Industrial Park is the final place where Longquan Celadon traditional firing techniques were inherited. It has well-preserved Gulong kiln group, local Qing Dynasty otter, porcelain clay mine, raw material processing workshop, and celadon handcraft workshop, which are still in use today, and become the most authentic celadon culture ecological specimen of Longquan Celadon traditional firing techniques. Longquan Celadon Cultural Industrial Park is the best preserved area of the Longquan celadon historical relics. Given its representativeness as well as uniqueness, the Longquan Celadon Cultural Industrial Park is taken as the case study for the theoretical and practical exploration of $\mathrm{ICH}$ protection.

\section{Methods and strategies}

While the global cultural heritage is concerned with the protection of cultural heritage that is man-made, tangible, and physical, the main concern of $\mathrm{ICH}$ is its non-physical elements such as spirit, artistry, and creativity, which exist as artistic or cultural expression forms [3]. It can be seen for itself has esthetic value, technical value, and artistic value, but it is also very easy to disappear under the impact of the modern thoughts since they are memories in the spiritual level [2]. Mr. Jicai Feng pointed out sharply: "The protection of intangible cultural heritage is mainly live protection, and the key to live protection is the heir." The intangible cultural heritage tourist attractions preserve and inherit the heir and existing living environment in an authentic way through specific geographical environment to protect unique cultural genes, cultural traditions, and national 
memories. Therefore, when building intangible cultural heritage tourist attractions, besides taking into account general characteristics of normal tourist attractions (as shown in the right column of Table 1), using digital means, it is even more necessary to highlight their own particularities in ICHs' cultural memory inheritance like locality, activeness, historical accumulation, etc. Digital means are used to properly handle the relationship between traditional cultural ecology systems and the dynamic change of OTAs (as shown in Fig. 1) [8-12].

In recent years, from a cognitive point of view, research emphasis has shifted from ICH protection to ICH tourism development because of domestic emphasis on protection and inheritance of ICH. In particular, it explores the inevitability of $\mathrm{ICH}$ tourism development from the perspective of economic value, and holds that $\mathrm{ICH}$ could find surviving ground in the real life only if $\mathrm{ICH}$ and tourism development reaches a win-win situation [4].
At present, the industry generally holds that the protection and development of ICH are in a dialectical and unified relationship [6]. The establishment of digital ICH can, to a certain extent, effectively promote the development of $\mathrm{ICH}$, and achieve a benign interaction between the two. The development of ICH tourism has experienced a shift from static development to live development, and from single mode to multi-integrated development mode [7]. However, we must prevent overloading and destructive exploitation of ICH due to tourism development, to avoid over-commercialization, artificialization and urbanization, and behaviors which arbitrarily distort folklore in the name of inheritance and innovation, and therefore greatly undermine the authenticity of ICH [9].

\subsection{The analysis of Longquan celadon $\mathrm{ICH}$ and tourism development status quo}

Longquan is located in the south-western part of Zhejiang Province, with a long history, rich cultural heritage, and

Table 1 The view spots classification of Longquan celadon industry cultural park

\begin{tabular}{|c|c|c|c|}
\hline Types & Subtypes & Basic types & Name of the tourism resource monomer \\
\hline B Waterfront scenery & BA River reach & $\begin{array}{l}\text { BAA River reach for sightseeing } \\
\text { and recreation }\end{array}$ & Badu stream \\
\hline \multirow[t]{3}{*}{ C Biolandscape } & CA Trees & CAA Woodland & Longquan bamboo \\
\hline & \multirow[t]{2}{*}{ CB/CC Flower area } & CBB Scarce forest and grassland & \multirow[t]{2}{*}{ Artificial construction } \\
\hline & & CCB Flower area in forest & \\
\hline $\begin{array}{l}\text { D Astronomy and } \\
\text { climate }\end{array}$ & DA Light phenomenon & DAA Observation site for heaven & Bamboo sunset, sunrise from green hill \\
\hline E Heritage site and relic & $\begin{array}{l}\text { EB Heritage sites of } \\
\text { socioeconomic cultural activities }\end{array}$ & EBD Abandoned industrial land & The ZengQinKee ancient kiln \\
\hline \multirow{4}{*}{$\begin{array}{l}\text { F Architecture and } \\
\text { facilities }\end{array}$} & \multirow{2}{*}{$\begin{array}{l}\text { FA Synthetic human culture } \\
\text { tourism site }\end{array}$} & FAB Recreation and vacation resort & Piyun mountain villiage \\
\hline & & $\begin{array}{l}\text { FAF Construction project and } \\
\text { production land }\end{array}$ & $\begin{array}{l}\text { The community of the Shangyang State-run } \\
\text { Celadon Plant }\end{array}$ \\
\hline & FD Residence and community & FDA Traditional and local architecture & Yuandi village, historic village behind the plant \\
\hline & FG Hydraulic architecture & FGF Water extraction facility & Millstones fang, Big wheel car \\
\hline \multirow[t]{3}{*}{ G Tourist commodities } & \multirow[t]{3}{*}{ GA Local Tourist commodities } & GAA dish and beverage & Huang ke, Barilla zongzi, Cha Er frozen, etc. \\
\hline & & $\begin{array}{l}\text { GAB Agricultural, forestry and } \\
\text { livestock products and products }\end{array}$ & $\begin{array}{l}\text { Longquan letinous edodes, Auricularia, } \\
\text { bamboo shoots and tea }\end{array}$ \\
\hline & & $\begin{array}{l}\text { GAE Traditional handicraft and } \\
\text { handicraft }\end{array}$ & $\begin{array}{l}\text { Green porcelain (practical porcelain, stationery } \\
\text { porcelain, furnished porcelain, porcelain for } \\
\text { porcelain, entertainment porcelain, etc.) }\end{array}$ \\
\hline \multirow[t]{6}{*}{ H Human activities } & \multirow[t]{2}{*}{ HA Personnel records } & HAA Character & $\begin{array}{l}\text { Ye Qingji, Zhang Shengyi, Zhang } \\
\text { Shenger, Celadon }\end{array}$ \\
\hline & & HAB Event & The history of celadon \\
\hline & \multirow[t]{3}{*}{ HB Arts } & $\begin{array}{l}\text { HBA Literature and art } \\
\text { organization }\end{array}$ & "Celadon Music," a celadon band \\
\hline & & $\begin{array}{l}\text { HBB Literature and artistic } \\
\text { works }\end{array}$ & $\begin{array}{l}\text { The articles and poems of Lu Yu and } \\
\text { Qian Long Emperor }\end{array}$ \\
\hline & & HBZ Handcraft art & $\begin{array}{l}\text { The art of celadon burning, the art } \\
\text { of celadon decoration }\end{array}$ \\
\hline & HC folk custom & HCA Local custom & $\begin{array}{l}\text { The worship of touts, choose kilns, } \\
\text { offering meals, kiln, she ethnic } \\
\text { minority group }\end{array}$ \\
\hline
\end{tabular}




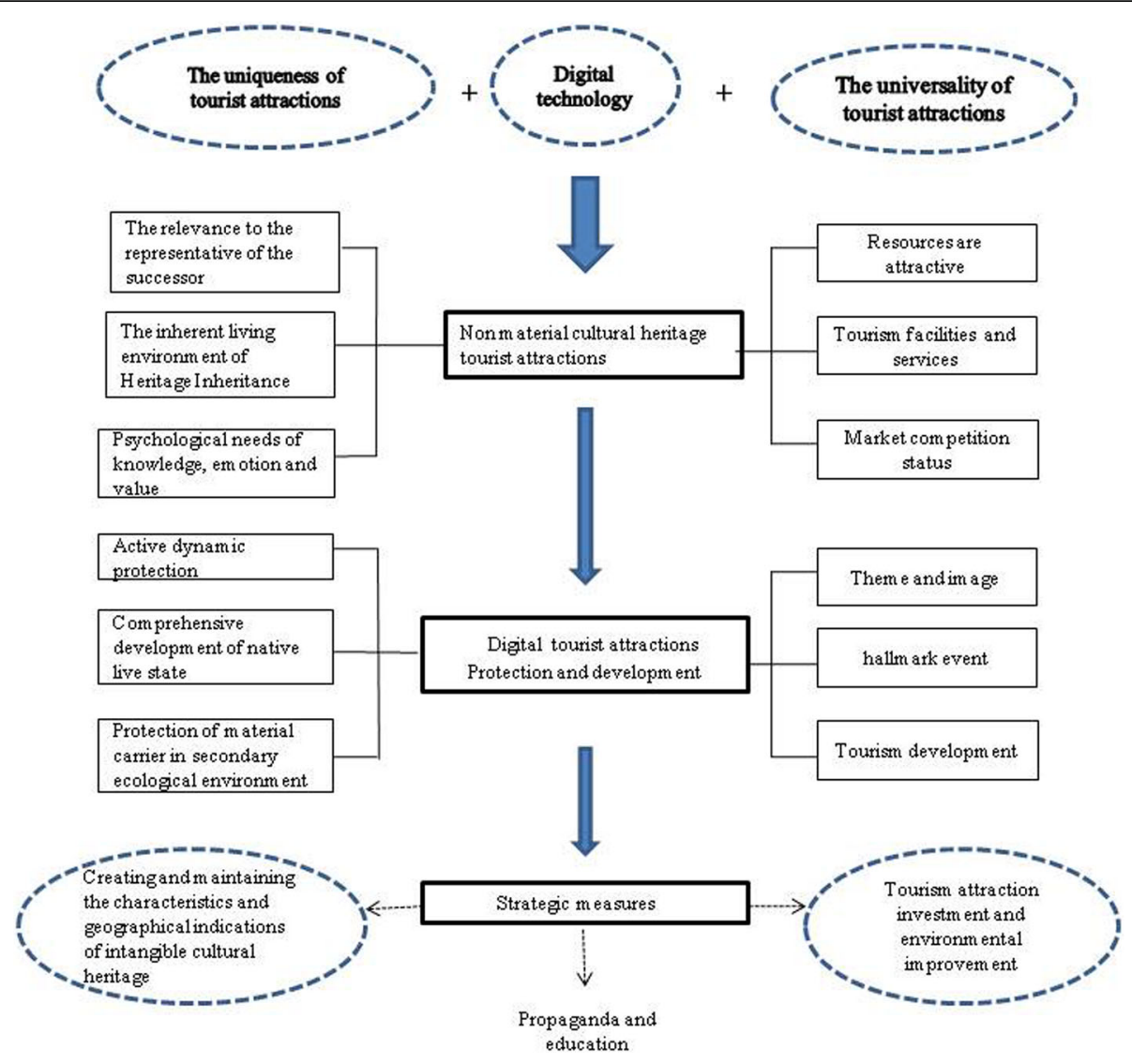

Fig. 1 Construction of digital tourist attractions of $\mathrm{ICH}$

beautiful scenery. It is also known for having bred two famous Longquan culture, "Sword" and "Celadon." The city has a total area of $3059 \mathrm{~km}^{2}$. By the end of 2016, there were 290,700 registered permanent residents with a total GDP of 11.88 billion Chinese Yuan, and 37,406 Chinese Yuan per capita disposable income for urban residents. Relying on unique resource advantages and cultural advantages, Longquan in 2016 welcomed 561.09 million tourists, and realized tourism revenue of 5.049 billion Chinese Yuan. There are four tourist attractions rated grade A or above, related to Longquan celadon, among which, two are national 4A level tourist attractions. The scenic area of Longquan Celadon Industrial Park is the core area that a unique Chinese celadon town is being built. It is worth to study as to how to rely on the digital protection of the Longquan Celadon ICH, and its integration with the tourism development, through digital photography, 3D information acquisition and high-fidelity holographic storage technology, virtual reality, multimedia display, and other means, to enable people to get a better tourism experience, and at the same time gain a more profound and comprehensive understanding of the ICH.

Longquan Celadon Industrial Park Scenic Area, located in Shangyang town, Longquan City, is the core tourist attraction of China (Shangyang) celadon town with a total area of about 60.24 ha. The scenic area has the scenic sites including the Zengqin ancient kiln site, Yuandi Village ancient aboriginal living sites, the modern Longquan Celadon Museum built on the state-run Longquan Celadon Factory heritage, the Piyun Celadon Village, and other attractions, having rich $\mathrm{ICH}$ resources, in which Piyun Celadon Village was selected "2009 Zhejiang Province Intangible Cultural Tourism Classic Scenic Area," becoming a model of Longquan celadon culture.

Tourism resource optimization is the core content of tourism planning, which integrates the natural resources, human resources, and material resources within the scenic area of Celadon Industrial Park, and meet the needs and improve the satisfaction level of tourists through the three-dimensional visualization of real scenic area.

\subsection{Tourism resource analysis and evaluation \\ 2.2.1 High ancient celadon status}

China is known as the "porcelain country," while Longquan celadon is a bright pearl in the porcelain kingdom. Ge kiln with a celadon tradition, together with Ru kiln, kiln, kiln and Jun kiln, is known as the five famous kilns of the Song Dynasty. Longquan celadon has a long history, 
and began to burn porcelain in the Western Jin Dynasty. It became the largest porcelain center in the country during the Southern Song Dynasty, and became the largest kiln in the South Song Dynast. The famous Da kiln at that time stretched from the GaojiTou to the AuTau Village, lasting 10 miles along a creek, with 53 kiln sites densely located. As "Longquan County Annals" records: "Porcelain kilns is everywhere along the two banks of Oujiang River, with smoke and fire on sight and porcelain transportation vessels fulling the river." By the mid-Ming Dynasty, the porcelain made in Jiangxi Jingdezhen became popular, and Longquan celadon had gradually been replaced by Jingdezhen blue and white porcelain and color porcelain replaced, and gradually weakened. As a result, its digital protection becomes an urgent mission.

\subsubsection{Rich heritage resources}

The ZengQinKee ancient kiln at Shangyang town built in the Qing Dynasty site is currently the dragon kiln with longest burning time at Longquan, well preserved and still in use. In the early 1950s, Prime Minister Zhou Enlai instructed "to resume the production of Longquan celadon which is on the verge of extinction." The local government set up a large-scale state-owned porcelain factory in the town of Shangyang, $36 \mathrm{~km}$ west of Longquan City. After more than 60 years of development, the plant has not only become the production base of China but also has cultivated a group of the national art and craft masters with world reputation, such as Chaoxing $\mathrm{Xu}$ and Zhengcong Mao, leaving a noteworthy legacy in the celadon history. The existing remains of porcelain factory buildings, research institute, expert dormitories, dragon kilns, inverted flame kiln, water mound, and other relics remain intact, becoming a witness to the history of non-replicable celadon culture, and make it possible for the information of the heritage and inheritors being passed to tourist effectively and authentically in a variety of ways.

\subsubsection{Rich humanity and cultural resources}

Longquan celadon has a unique history and culture and spiritual connotation, including legendary stories, poetry and literature, the thoughts of the five elements of heaven and earth, and the morality of Confucianism and Taoism. By digging the history, culture, and spirit behind the celadon culture, and integrating it into the scenic area's functional layout and tourism product planning will enrich and enhance the quality of the scenic area.

\subsubsection{Superior landscape resources}

The town of Shangyang where Longquan Celadon Industrial Park is located has a unique landscape resource and superior ecological environment with a forest coverage rate of nearly $80 \%$, and with reputations such as "Hometown of bamboo," "land of mushrooms," and "Eastern Oxygen Bar."

\subsection{Market analysis and positioning}

With the increasing income of residents, and the rapid growth of cultural tourism demand in China, it has brought opportunities for the development of tourism resources for $\mathrm{ICH}$. At the same time, Lishui City has established a "Five Lines and One Hub" railway pattern during the "12th Five-Year Plan" period. Convenient transportation greatly shortened the "space-time distance" as well as "psychological distance," and brought tremendous room for improvement and late-development advantage in the tourism development of Longquan, which largely contributed to the $25 \%$ and $33 \%$ total tourism revenue annual growth rate in Longquan in the past 2 years (see Fig. 2). Applying the growth rate formula (1), the tourist volume in the next 10 years is estimated, as shown in Table 3.

Therefore, the target markets of Longquan Celadon Industrial Park are as follows: the Yangtze River Delta region around Shanghai and Hangzhou as the core market, northern Fujian, eastern Jiangxi, the Bohai Sea, the Pearl River Delta region as the key markets, other parts of the country and Southeast Asia, Japan and South Korea,

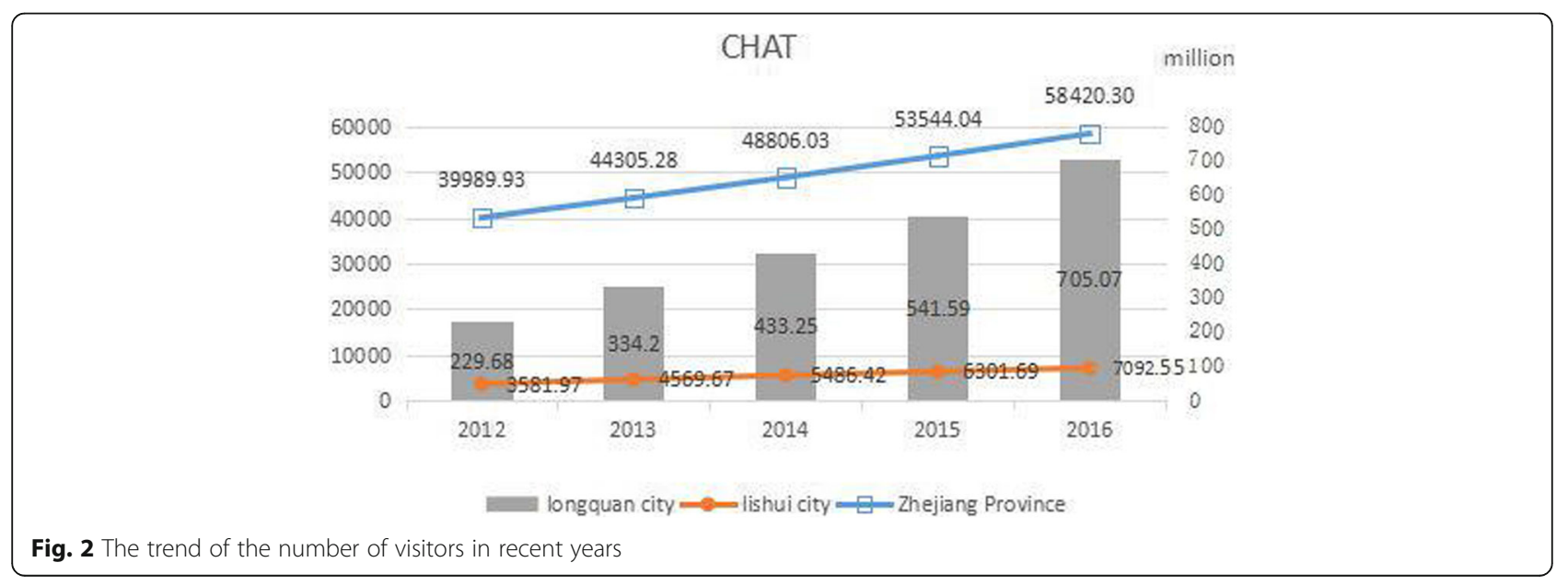


Europe and the USA, and other overseas markets as the opportunity markets. And heritage cultural experience, ecological landscape sightseeing, scientific investigation and study, leisure and health tourism, business travel, and other diversified tourism product models is being created to promote the regional tourism development.

Applying the growth rate formula (1) and (2), the estimated number of tourists is listed in Table 2.

$$
\begin{aligned}
& B_{j}=A_{i}(1+X)^{n} \\
& X=\frac{\left|A_{i}-B_{j}\right|}{A_{i}}
\end{aligned}
$$

in which $A_{\mathrm{i}}$ is the number of visitors in the baseline year, $X$ is the average annual growth rate, $n$ is the number of years, and $B_{\mathrm{j}}$ is the number of visitors in a future year.

\section{Discussion and experiments results}

The protection of $\mathrm{ICH}$ and tourism development are opposite and unified. Emphasizing authenticity is the foundation and core, and the basis of tourism development. Digital tourism development is the development and extension of authenticity. As long as digital tourism development adheres to authenticity, the protection of $\mathrm{ICH}$ and tourism development can become unified from the opposite sides [2,6]. Therefore, it is imperative to keep ancient kiln sites such as ZengQinJi, and at the same time consolidate with the grand production occasions of Longquan Celadon in 1957 to preserve the historical memory, which highlights the unique position of Shangyang in the Longquan Celadon development history.

Protection as the priority, rational utilization, and development with inheritance are the three guidelines of scenic area planning. It should apply the advanced IT technology and think out of the traditional static protection framework to establish a resource and market-oriented, innovative Longquan celadon live protection and inheritance system, in combination with the geographical environmental

\begin{tabular}{|c|c|c|c|}
\hline \multicolumn{2}{|l|}{ Developmental stage } & $\begin{array}{l}\text { Short-term } \\
(2016-2020)\end{array}$ & $\begin{array}{l}\text { Long-term } \\
\text { (2021-2025) }\end{array}$ \\
\hline \multicolumn{2}{|c|}{ The total visitor numbers (million/year) } & 45 & 65 \\
\hline \multirow{5}{*}{$\begin{array}{l}\text { Final source prediction } \\
\text { (million/year) }\end{array}$} & Cultural experience & 12 & 18 \\
\hline & Scenic sightseeing & 5 & 10 \\
\hline & $\begin{array}{l}\text { Environmental } \\
\text { education }\end{array}$ & 3 & 5 \\
\hline & $\begin{array}{l}\text { Recreation and } \\
\text { vacation }\end{array}$ & 9 & 18 \\
\hline & Business conference & 6 & 13 \\
\hline \multicolumn{2}{|c|}{ End-of-term spending per pers (Yuan) } & 1000 & 1300 \\
\hline \multicolumn{2}{|c|}{ Final tourism revenue ( $\$ 100$ million) } & 4.5 & 8.5 \\
\hline
\end{tabular}

Table 2 Visitor volume forecasts

Derived from the author's research data characteristics, to promote the regional linkage and tourism industry integration and expansion, and thus achieve sustainable development of the scenic area [9].

$\mathrm{ICH}$ often has the comprehensive functions of humanity and culture, aesthetician, history, entertainment, recreation, education, and science. Based on the needs of tourists, the spiritual elements of $\mathrm{ICH}$ can be integrated into tourists' traveling, playing, entertainment, shopping, eating and accommodation, and other tourism experiences through virtual reality technologies, to give tourists opportunities to learn and gain perception of celadon, realizing the spiritual interaction of people, and the history [10].

\subsection{Digital scenic area planning objectives and technical analysis}

Celadon Industry Cultural Park at Shangyang is an important part of the Longquan celadon development history. It is a blessed land for the revival of the celadon industry in Longquan, and also the live carrier of the celadon culture in the specific historical development stage. The goal of the planning is to digitally import ICH celadon culture, integrate and utilize natural and cultural resources, cultivate a diversified heritage tourism product system, create a 3D visualization of national cultural tourism scenic area with integrated functions of history exploration, culture display, art creation, and leisure and vacation, to realize the digital protection and inheritance of $\mathrm{ICH}$ and the sustainable development of tourism industry [7]. The terrain features in the GIS are extracted to form the basic characteristics for environmental spatial analysis, and virtual reality (VR) technology can be applied to generate a specific range virtual environment with realistic sensations. The user uses the necessary equipment to naturally interact with objects in the virtual environment to create a feeling and experience that is close to the real environment $[8,9]$.

Figures 3, 4, and 5 show that 3D visualization technology can be merged into the digital scenic area integrated system planning management by combining tourist attraction planning with virtual geographical environment.

\subsection{Space layout and project introduction of digital scenic area}

The natural and cultural resources in different areas of the whole celadon town are utilized and integrally planned. With the Baidu Creek Waterfront Landscape Belt as the main axis, a diversified tourism product system is created integrating sightseeing, culture, experience, and recreation, forming eight areas from North to South including tourist service area, leisure landscape experience area, celadon culture experience exhibition area, the ancient village folk customs area, the artist creation area, celadon cultural health area, waterfront leisure landscape belt, and ecological forest reservation area. (For details, see Table 3, Figs. 3 and 4). 


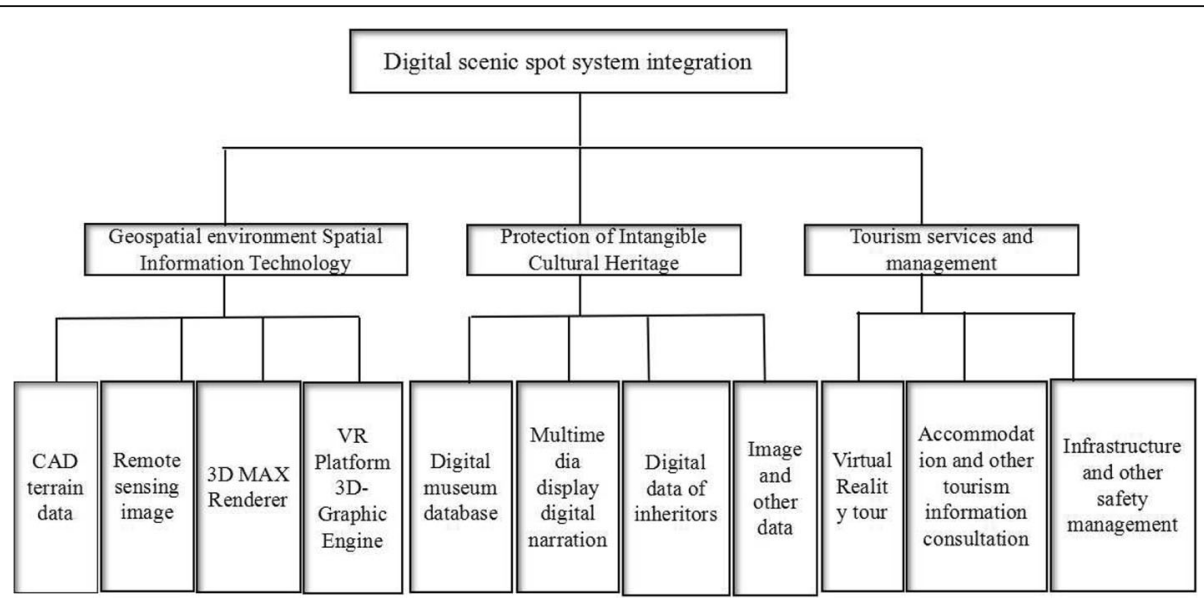

Fig. 3 Digital tourist attraction system integration map

\subsection{Digital scenic area tourism development strategy}

\subsubsection{Priority for cultural inheritance, and development of} experiential cultural eco-tourism with both real and virtual reality

Cultural ecotourism emphasizes complete protection of ICHs, which not only protects the ICH but also protects its carrier and the material and cultural heritage closely related to its inheritance. At the same time, it is necessary to protect the natural environment and humanity and cultural environment on which the cultural heritage depends. Through the reservation and upgrade of Celadon Dream Valley and Celadon Research Institute, and the overall integration of Binshui wetlands with ecological forests, etc. Cultural ecotourism focuses on the protection of cultural authenticity, integrity, and original ecology in the tourism product creation and project set-up to maintain cultural diversity and culture ecological balance, and at the same time, introduce the real scenery into the digital scenic system, and develop virtual reality simulation scene experience to meet the cultural experience needs of tourists in different levels [12].

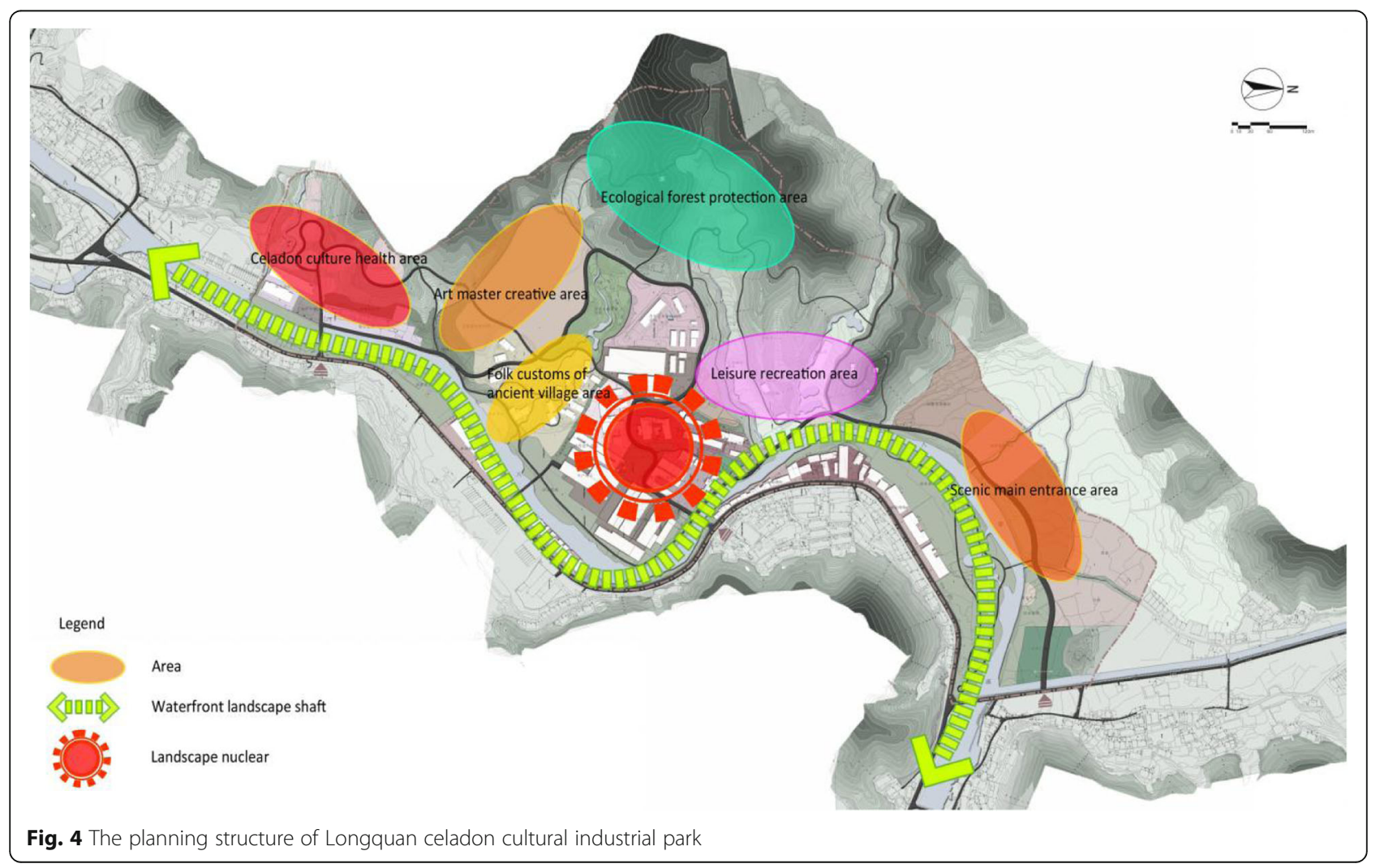




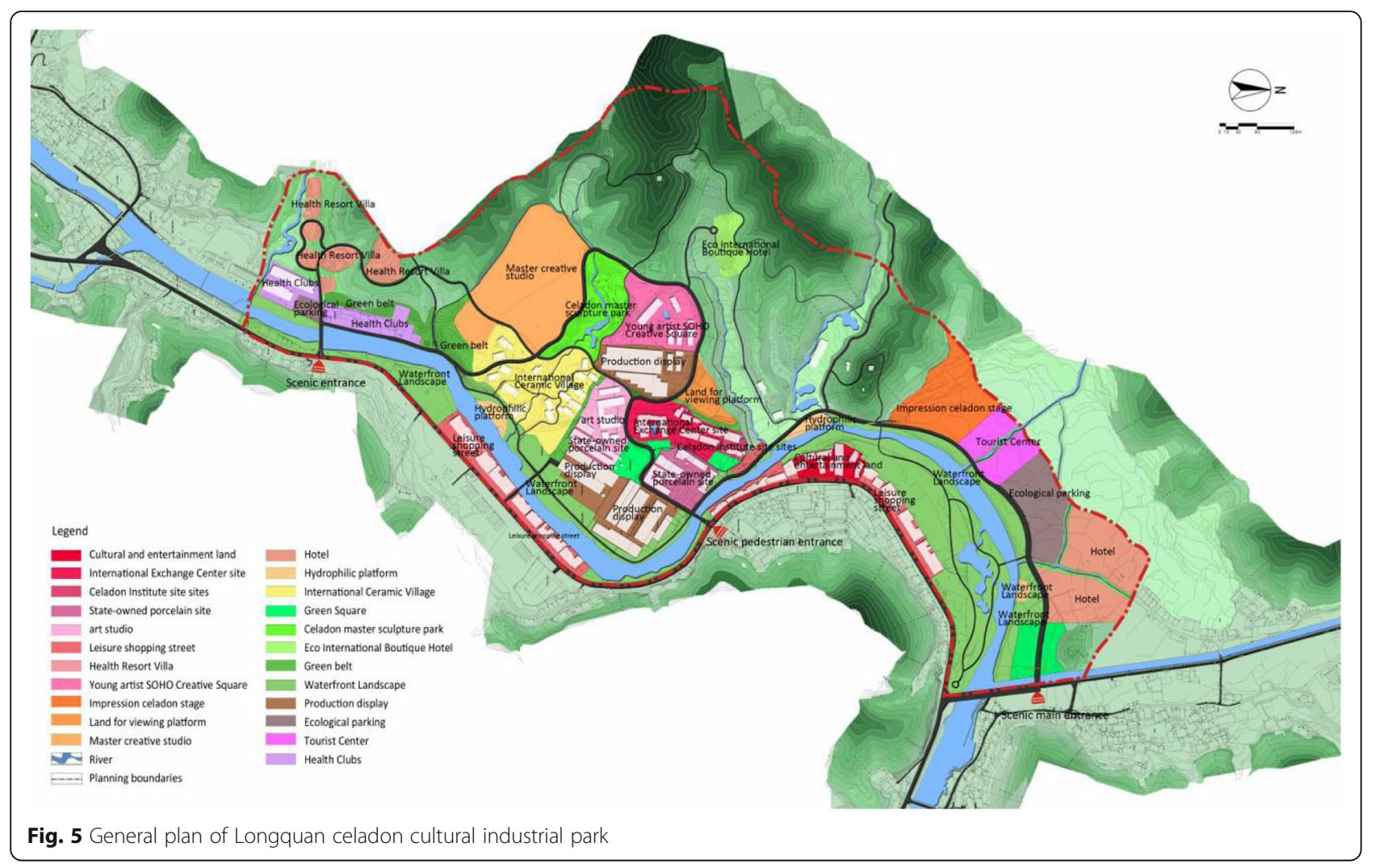

The authenticity of the ICH is closely related to the region, and its spatial information attributes must be emphasized. In the G/S mode, G is the GIS geoscience browser or spatial information browser. Data browsing can highlight the distribution of ICH resources, its historical migration, and help improving understanding of the $\mathrm{ICH}$ information by combining the natural and historical environment changes. G not only has all the functions of a web browser but also has a strong three-dimensional display and interaction capability, which enables the integration of spatially heterogeneous data into sharable information. $\mathrm{S}$ is the distributed spatial information server group, which is the background data management and scheduling system in G/S mode, and is the service and management terminal of a digital scenic area.

\subsubsection{Live protection, combination of actual and virtual situation, comprehensive diversified tourism development model}

Liveliness is the most basic feature of $\mathrm{ICH}$. The people-oriented development and protection model is the fundamental model for the protection and development of all types of $\mathrm{ICH}$. Longquan Celadon belongs to the $\mathrm{ICH}$ project of the traditional craftsmanship type, and should be protected in production. The preservation of the ancient kiln, ZengQinJi that is still in production, and the production plant in the 1960 s with their production function restored, is how $\mathrm{ICH}$ as a live culture and living style is inherited and continued. Moreover, it is a way of live protection through the celadon fabrication theme tourism routes of the master creative studio, the International Ceramics Village, Celadon DreamWorks, and the SOHO workshop of young artists. It could also enrich the tourism connotation using high-tech means such as celadon treasure hunt and the celadon impression stage to enhance the heritage exhibition and publicity to meet the tourists' diversified celadon culture tourism experiences that are informative, fun, and interactive [13]. Longquan celadon can effectively cultivate and expand the audience of this $\mathrm{ICH}$, having more people understand, love, and even study Longquan celadon. At the same time, the heyday of Longquan Celadon kiln can be restored in the simulation scene using digital technology, allowing visitors to freely switch between the spaces, realizing the integration of history and reality.

\subsubsection{Establish effective project operation and management mechanism}

It is desirable to learn from the successful experience of other domestic tourist attractions regarding the operation and management system, and establish a project operation and management mechanism that is government-guided, market-oriented, and enterprise-oriented. The corresponding scenic area information can be found through the query 


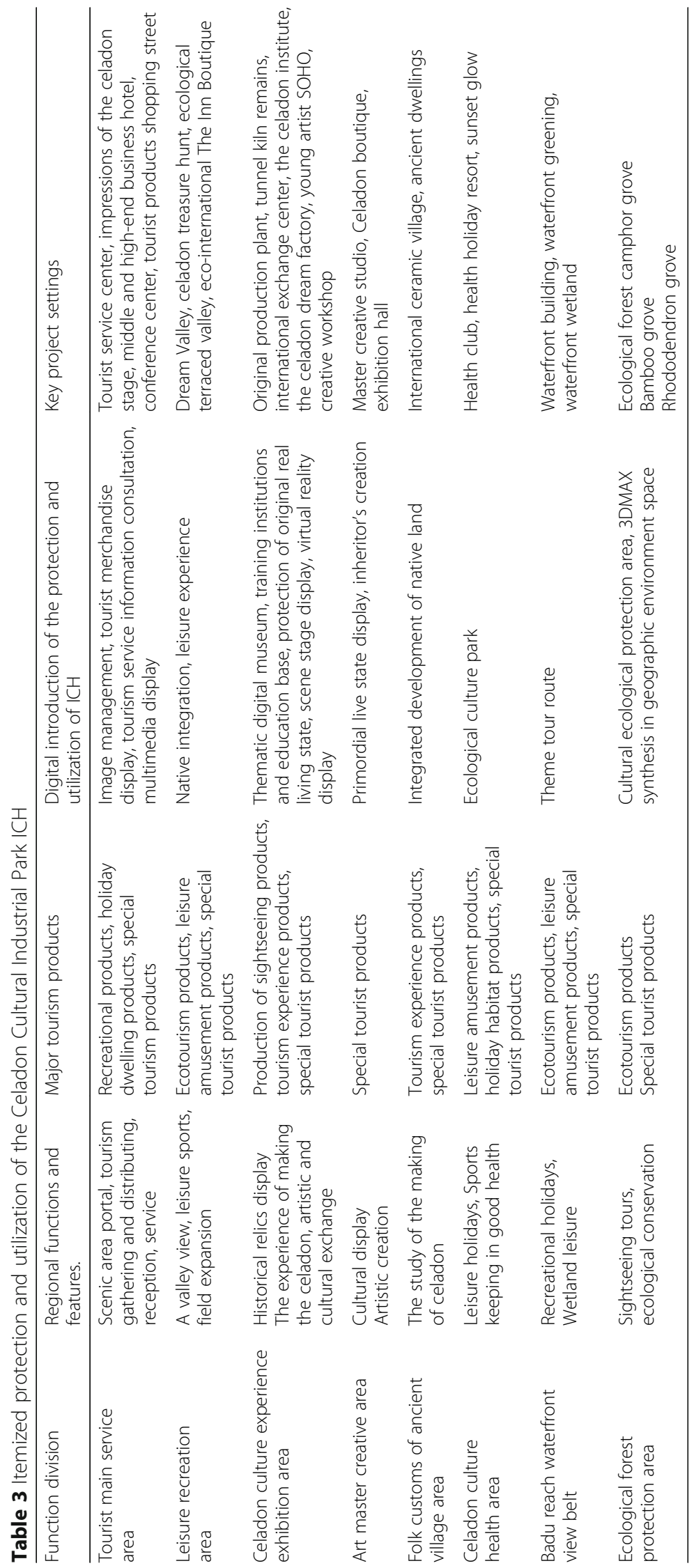


function of the GIS, including attribute data-based query and visual graphic data-based query. The integrated management of geospatial space can be realized through the eagle eye navigation map to support the scenic area tourism service function development and management. It is suggested that government departments fully utilize macroeconomic regulation and control, coordinating the conflicts between the development of private enterprises, and the overall objective of scenic area development in the course of project development and operation, so as to establish a market-oriented operation platform for tourism operators, and include private enterprises in the overall development of tourist attractions, realizing the benefit sharing of tourist attraction development $[14,15]$.

\subsubsection{Strengthen marketing and publicity, and expand the tourist market with the digital scenic area construction}

Through the planning of Celadon stage show, the World Celadon Art Biennale, Celadon Master Show, international conferences, and other festivals, shows, and activities, the scenic area image and brand can be enhanced. At the same time, the popularity of the scenic area can be elevated through the promotion of China and Zhejiang brand, and integration with other tourist attractions in Longquan city, and through enhanced publicity, to attract tourists from different areas, especially vacation tourists [16].

\section{Conclusion}

The ICH tourism development is of great significance. With proper environmental space planning and selection and project introduction, and a reasonable comprehensive tourism experience model, it can not only create a good surviving environment for $\mathrm{ICH}$, providing funding security, but also promote full exploitation of the value of $\mathrm{ICH}$. It is an important way to inherit and develop ICH.

It is currently a hot but challenging topic to protect $\mathrm{ICH}$ and promote tourist attraction development at the same time, with the digital tourist attraction construction as the core through application of multimedia, internet, database and VR technologies, and so on. In the early 1990s, Faust and Koller successfully integrated GIS and VR systems, and proposed the concept of VR-GIS. At present, the digital scenic area operation of Celadon Industrial Park is mainly based on VR-GIS platform. It uses VR technology as the front-end to interact with users, and supports GIS spatial data storage, processing, query, analysis, and other functions to establish a comprehensive VR, 3D GIS, and multidimensional visual information and spatial technical system. The abstract geographic information is easier to perceive with the geographical environment being expressed by 3D graphics through the construction of virtual terrain environment. The adoption of multi-sensory channel space sensing technology could create a strong sense of immersive visual perception of Longquan Celadon manufacturing environment and technical process flow, and thus enable unification of tourists' visual perception of the realistic park space with their logic perception which creates the most memorable memory of the $\mathrm{ICH}$. In the tourism project and development strategy planning, it is advantageous to use digital means in implementing the thought of "protect and utilize," and find the balance between ICH protection and tourism development.

\section{Abbreviations \\ 3D: 3-Dimension studio; CAD: Computer-aided design; G/GIS: Geographic information system; ICH: Intangible cultural heritage; OTA: Ordinary tourist attractions; SOHO: Small office, home office; VR: Virtual reality}

\section{Acknowledgements}

The authors thank the editor and anonymous reviewers for their helpful comments and valuable suggestions.

\section{Funding}

The research presented in this paper was supported by Longquan Tourism Bureau, Zhejiang Province, China.

\section{Availability of data and materials}

Please contact author for data requests.

\section{About the authors}

Yue Zhang, female, Associate Professor, the Director of Urban and Rural Planning and Environmental Landscape Research Institute, Zhejiang University City College, Hangzhou, China, Email address: zhangyue@zucc.edu.cn.

Mingqing Han, male, Senior Engineer, corresponding author, the Director of Urban Management Research Center, Zhejiang University City College, Hangzhou, China. Email address: hmq@zucc.edu.cn.

Weiwei Chen, female, principal staff member of Hangzhou Formulation center of Urban Planning, Hangzhou urban planning bureau, Hangzhou, China.

\section{Authors' contributions}

$Y Z$ is the main writer of this paper. She proposed the main idea, deduced the performance of digital scenic area planning, and analyzed the strategies. $\mathrm{MH}$ gave some important suggestions, introduced the view spots

classification and itemization. He is the corresponding author. WC carry out material collection and basic arrangement, draw corresponding drawings and forms. All authors read and approved the final manuscript.

\section{Competing interests}

The authors declare that they have no competing interests.

\section{Publisher's Note}

Springer Nature remains neutral with regard to jurisdictional claims in published maps and institutional affiliations.

\section{Author details}

${ }^{1}$ Zhejiang University City College, Hangzhou, Zhejiang, China. ${ }^{2}$ Hangzhou Formulation Center of Urban Planning, Hangzhou, Zhejiang, China.

Received: 31 July 2018 Accepted: 23 October 2018

Published online: 20 November 2018

\section{References}

1. M. Brewer, Intergroup relations, 2nd edn. (Open University Press, Oxford, 2003)

2. G. Cozzani, F. Pozzi, et al., Innovative technologies for intangible cultural heritage education and preservation: the case of i-Treasures. Personal Ubiquit. Comput. 21(2), 253-265 (2017)

3. M. Severo, T. Venturini, Intangible cultural heritage webs: comparing national networks with digital methods. New Media Soc. 18(8), 1-20 (2015) 
4. D. Aph, B. Dacia, The importance of the intangible cultural heritage in the economy. Procedia Econ. Finance 39, 731-736 (2016)

5. D. Adrian, E. Chamari, et al., Confucius computer: a philosophical digital agent for intergenerational philosophical play. Pers. Ubiquit. Comput. 21, 327-343 (2017)

6. K. Fahlquist, T. Mejtoft, J. Karlsson, Social media game concept within the digital zoo: new ways of connecting a tourist attraction with its visitors. Internet Things, 170-177 (2011). 2011 IEEE International Conferences on Internet of Things, and Cyber, Physical and Social Computing

7. L.G. Tomás, G.S. Francisco, Visitors' experiences with intangible cultural heritage: a case study from Córdoba, Spain. J Herit Tour. 20(6):1-6 (2016)

8. Y. Zhu, Z.F. Huang, Application of virtual reality technology on digital scenic spot. Appl. Mech. Mater. 333-335, 702-706 (2013)

9. W. Weiwu, Managing soil erosion potential by Integrating digital elevation models with the southern China's revised universal soil loss equation - - a case study for the West Lake scenic spots area of Hangzhou, China. J. Mountain Sci. 4(3), 237-247 (2007)

10. V.B. Rekha, A.P. Thomas, M. Suma, H. Vijith, Integration of spatial information technology for groundwater potential and quality investigations in Koduvan Ár sub-watershed of Meenachil River Basin, Kerala, India. J. Indian Soc. Remote Sens. 39(1), 63-71 (2011)

11. Y.U. Hai-feng, X.I.N.G. Gui-fen, Z. Kai, Application of virtual reality technology in scenery simulation system. Comput. Eng. Des. 27(6), 1108-1110 (2006)

12. T.M. Schmitt, The UNESCO concept of safeguarding intangible cultural heritage: its background and Marrakchi roots. Int. J. Herit. Stud. 14(2), 95111 (2008)

13. I.N. Abuamoud, J. Libbin, J. Green, R. Alrousan, Factors affecting the willingness of tourists to visit cultural heritage sites in Jordan. J. Herit. Tour. 9(2), 148-165 (2014)

14. S.H. Mateja, B. David, P. Pipan, Sustainable heritage management: social, economic and other potentials of culture in local development. Procedia Soc. Behav. Sci. 188, 103-110 (2015)

15. L. Nicholas, B. Thapa, Visitor perspectives on sustainable tourism development in the pitons management area world heritage site, St. Lucia. Environ. Dev. Sustain. 12, 839-857 (2010)

16. A. Chianese, F. Piccialli, I. Valente, Smart environments and cultural heritage: a novel approach to create intelligent cultural spaces. J. Locat. Based Serv. 9(3), 209-234 (2015)

\section{Submit your manuscript to a SpringerOpen ${ }^{\circ}$ journal and benefit from:}

- Convenient online submission

- Rigorous peer review

- Open access: articles freely available online

High visibility within the field

- Retaining the copyright to your article

Submit your next manuscript at $\boldsymbol{\nabla}$ springeropen.com 